\title{
Um computador por aluno: o Projeto Político-Pedagógico das escolas
}

\author{
Silvana Donadio Vilela Lemos*
}

\section{Resumo}

Inicialmente, pretende-se apresentar alguns argumentos sobre a importância do Programa Um Computador Por Aluno, como política pública que se propóe a democratizar o acesso e possibilitar a inclusáo digital de gestores, professores e alunos da escola pública no Brasil. Em seguida, anunciar a proposta de integração das TIC nos documentos que retratam o Projeto Político-Pedagógico, em três escolas dos estados de Goiás, São Paulo e Tocantins. O presente artigo é o resultado da primeira etapa do projeto de pesquisa intitulado A sala de Aula no Século XXI: Inovação e Criticidade, aprovado pelo Programa Nacional de Pós-Doutorado (PNPD), de 2010, edital n. 001/2010 (MEC/CAPES e MCT/CNPq/FINEP), que incentiva o participante a realizar uma pesquisa documental sobre a integração das TIC ao currículo da Educação Básica, no Projeto Político-Pedagógico das escolas. A metodologia empregada neste projeto constituiu-se na análise de documentos que retratam o Projeto Político-Pedagógico das seguintes escolas: Escola C. E. M. Professora Neyde Tonanni Marão, no estado de São Paulo, Escola Estadual Presidente Costa e Silva, de Tocantins, e o Colégio Estadual Roque Romeu Ramos, de Goiás. Com base na análise dos documentos das escolas, depreende-se que consideram imprescindível registrar no Projeto Político-Pedagógico a relevância do acesso aos avanços científicos e tecnológicos, como saberes e habilidades para que o aluno exerça sua cidadania de forma plena, no século XXI. Porém, evidencia-se a necessidade de informaçóes sobre as açóes desenvolvidas, as dificuldades e soluçóes apresentadas, como também os avanços alcançados e os desafios presentes.

Palavras-chave: Projeto Político-Pedagógico, tecnologia de informação e comunicação.

A computer per student: the pedagogical policy project for schools

\section{Abstract}

This paper first presents some arguments about the importance of the program "A Computer per Student", as a public policy which proposes to democratize access and facilitate the

* Doutora pela Pontifícia Universidade Católica de São Paulo, Programa Educação: Currículo. Bolsista pelo Programa Nacional de Pós-Doutorado (PNPD), vinculado à instituiçấo Pontifícia Universidade Católica de São Paulo.E-mail: sil.lemos@uol.com.br. 
digital inclusion of Brazilian public school managers, teachers and students. It then goes on to present the proposal for integrating ICT into documents presenting the Pedagogical Policy Project in three schools in the States of Goiás, São Paulo and Tocantins. This article is the result of the first stage of a research project entitled The classroom of the 21 st century: Innovation and Criticality, approved by the National Post-graduate Program by Public Notice number 001/2010, of the Ministries for Education and Science and Technology, which encourage participants to undertake a desk research on the integration of ICT into the curriculum of Basic Education in the Pedagogical Policy Project in schools. The methodological framework used in this project was the analysis of documents presenting the Pedagogical Policy Project of the following schools: Professora Neyde Tonanni Marão Municipal School, Sáo Paulo; President Costa e Silva State School, Tocantins, and Roque Romeu Ramos State School, Goiás. Based on an analysis of the school documents, it could be deduced that for these schools it is essential to register the relevance of access to scientific and technological advances as knowledge and skills in their Pedagogical Policy Project so that students can exercise their citizenship to the full in the 21 st century. However, the need for information about the activities carried out and the difficulties and solutions presented, as the achievements reached and the challenges met is also highlighted.

Keywords: pedagogical policy project, information and communication technology.

\section{Introdução}

Inicialmente, pretende-se apresentar alguns argumentos sobre a importância do Programa Um Computador Por Aluno (Prouca), como política pública que se propóe a democratizar o acesso e possibilitar a inclusão digital de gestores, professores e alunos da escola pública no Brasil. Em seguida, anunciar a proposta de integração das Tecnologias de Informação e Comunicação (TIC) nos documentos que retratam o Projeto Político-Pedagógico, em três escolas dos estados de Goiás, São Paulo e Tocantins.

O presente artigo é o resultado da primeira etapa do projeto de pesquisa intitulado A Sala de Aula no Século XXI: Inovação e Criticidade, aprovado pelo Programa Nacional de Pós-Doutorado (PNPD), de 2010, edital n. 001/2010 (MEC/CAPES e MCT/CNPq/FINEP), que incentiva que o participante possa realizar uma pesquisa documental sobre a integraçáo das TIC ao currículo da educação básica, no Projeto Político-Pedagógico das escolas.

O governo federal, desde o ano de 2007, tem como uma de suas estratégias para inclusão digital na educação o Programa Um Computador Por Aluno (Prouca), que se propóe a disponibilizar, por aluno, um pequeno laptop educacional, fornecido por diferentes fabricantes.

Almeida e Valente (2011, p. 26-27) relatam os resultados de alguns estudos sobre o uso do laptop por aluno, permitindo afirmar que a integração 
dele às práticas educativas modifica, de forma significativa, a dinâmica da sala de aula. $\mathrm{O}$ uso individualizado pelos alunos contribuiu, de forma significativa, para o letramento digital, a autonomia ao acesso de informaçóes on-line e à escrita dos alunos.

Os projetos que integraram o uso do laptop educacional, com atividades complementares, fora de sala de aula, estimularam o aluno a ler, escrever mais e impulsionaram sua autonomia em buscar o conhecimento. Além disso, imprescindíveis para que o aluno avançasse na aprendizagem foram o apoio e o feedback do professor em relação às suas dúvidas e produçóes escritas. $\mathrm{O}$ autor considera que esses novos ambientes de aprendizagem abrem caminhos a uma educação criativa, inovadora e incentivam a autonomia e o fortalecimento da autoestima do aluno na busca pelo conhecimento. Portanto, inibe a reprovação e a evasão escolar.

Almeida e Valente (2011, p. 51) expressam que o laptop proporciona novas possibilidades de conectividade e mobilidade e convidam o professor a romper e criar desafios educacionais que aproveitem essa nova forma de se relacionar com a informação e comunicação a distância. As características agregadas, a partir desse novo contexto, são: o acesso fácil e instantâneo de informaçóes e conhecimentos, e a aprendizagem em qualquer lugar e tempo. "O contexto é o local no qual as conversações ocorrem. Porém, em vez de fixo, ele é moldado pelo diálogo continuamente negociado entre as pessoas e a tecnologia." (ALMEIDA e VALENTE, 2011, p. 31).

O caminho para inovar está em explorar esses novos espaços abertos à pesquisa, ao diálogo e à construção de uma rede colaborativa entre sujeitos que buscam pensar, compartilhar e construir conhecimentos significativos, para desvelar as problemáticas reais.

No Brasil, o maior desafio, segundo Almeida e Valente (2011), é a universalização do acesso e o uso das TIC pelos alunos, professores e estabelecimentos escolares. Nos casos em que já se iniciaram a implantação e implementação das açôes do Prouca, as dificuldades estão relacionadas à precária infraestrutura, ao número insuficiente de máquinas, à ausência de suporte técnico atento às necessidades da escola, aos problemas com a conexão de internet e ao sistema operacional que apresenta problemas em seus procedimentos.

Destaca-se, dentro desse contexto, o papel relevante do poder público em garantir aos professores um programa de formação permanente que os capacite, além de saber como, quando e a serviço do que integrar as TIC 
às práticas educativas, da mesma forma que atentar-se às contribuições e dificuldades que os alunos apresentam durante o ato de conhecer. "Este tipo de ensino é uma forma de reflexão-na-ação que exige do professor uma capacidade de individualizar, isto é, de prestar atenção a um aluno, mesmo numa turma de trinta, tendo a noção do seu grau de compreensão e das suas dificuldades." (SCHÖN, 2000, p. 82). Para completar o programa de formação dos professores, consideram-se fundamentais o espaço e o tempo para que os "achados", no decurso da ação educativa, sejam objeto de análise e estudo crítico. Por isso, privilegia-se o lócus da escola para o trabalho do "levantamento de temas de análise da prática que requerem fundamentaçáo teórica e a reanálise da prática pedagógica considerando a reflexão sobre a prática e a reflexão teórica” (FREIRE, 2001a, p. 81).

A partir dessa contextualização, tem-se a intenção de trazer argumentos sobre a não neutralidade de nossas escolhas e decisões na construção do Projeto Político-Pedagógico. E, logo em seguida, anunciar a integração das TIC e, em especial, o laptop educacional ao currículo, expressas nos documentos que retratam o Projeto Político-Pedagógico. E, para finalizar, pretende-se apresentar as contribuiçóes e os desafios presentes, a partir do processo construído nas escolas.

\section{Metodologia}

\section{A escolha das escolas}

Neste artigo, optou-se por analisar três documentos que retratam o Projeto Político-Pedagógico Um Computador Por Aluno de escolas, acompanhadas, direta e indiretamente pela Pontifícia Universidade Católica, instituição à qual o projeto de pesquisa de pós- doutorado PNPD 2010, MEC/ CAPES e MCT/CNPq/FINEP está vinculado.

Elegeu-se analisar o documento da escola C. E. M. Professora Neyde Tonanni Marão, em São Paulo, porque a PUC-SP é o instituto de ensino superior responsável pela formação dos professores e gestores da escola, dentro da dimensão local. Quanto à dimensão global, a PUC-SP é a instituição de ensino superior global que acompanha o desenvolvimento da equipe de formadores dos Núcleos de Tecnologia Educacional (NTE), dos estados de Tocantins e Goiás. Desse modo, foram disponibilizados pelos formadores dos 
núcleos os documentos das seguintes escolas: Escola Estadual Presidente Costa e Silva, em Tocantins, e Colégio Estadual Roque Romeu Ramos, em Goiás.

Para análise, optou-se pela abordagem qualitativa, haja vista que ela apresentou-se como a mais adequada para a investigação do objeto proposto por essa pesquisa.

A respeito da abordagem qualitativa, Bogdan (1994, p. 48-49) elucida:

Os dados incluem transcrições de entrevistas, notas de campo, fotografia, vídeos, documentos pessoais e oficiais e memorandos. Tentam analisar os dados em toda a sua riqueza, respeitando, tanto quanto possível, a forma em que estes foram registrados ou transcritos. A palavra escrita assume particular importância na abordagem qualitativa, tanto para o registro dos dados como para a disseminaçáo dos resultados.

Os pressupostos da pesquisa qualitativa permitem compreender a rica relaçáo entre o mundo real e os seres humanos, que incidem sobre os diversos aspectos da vida educativa.

\section{O conceito e a politização educativa do Projeto Político-Pedagógico}

Tem-se como objetivo inicial conceituar a concepção de Projeto Político-Pedagógico. A respeito disso, nossa compreensão aproxima-se do exposto por Vasconcelos (2009, p. 17-18):

O Projeto Político-Pedagógico é o plano global da instituição. Pode ser entendido como a sistematização, nunca definitiva, de um processo de planejamento participativo, que se aperfeiçoa e se objetiva na caminhada, que define claramente o tipo de ação educativa que se quer realizar, a partir de um posicionamento quanto à sua intencionalidade e de uma leitura da realidade.

Para esse autor, portanto, o Projeto Político-Pedagógico é o documento que anuncia e norteia as finalidades e as açóes e, portanto, as mudanças que o estabelecimento de ensino deseja implantar. É uma espécie de "guarda-chuva”, ao conter e garantir a articulação entre o particular e o global.

$\mathrm{O}$ autor considera, ainda, que não há consenso em relação ao nome, pois encontramos nos documentos dos estabelecimentos de ensino os 
seguintes (VASCONCELOS, 2009, p. 19): Projeto Político-Pedagógico, Projeto Pedagógico, Proposta Pedagógica, Projeto Educativo, Projeto de Escola, Projeto de Estabelecimento, Projeto Pedagógico-Curricular, Projeto Pedagógico-Administrativo, Projeto Pedagógico-Institucional, Plano Escolar, Plano Diretor, etc.

Freire (2001a, p. 41) expressa, na obra $A$ educação na cidade, que "não há administração ou projetos pedagógicos neutros". O autor afirma a natureza política da educação, pois há sempre opções e decisóes que alicerçam os objetivos e açóes educativas. Para ele, a natureza política do projeto educacional clama aos profissionais da educação a clareza, a coerência, a ética e o dever em decidir e lutar por uma formação humana que se comprometa com o desvelamento das experiências advindas do mundo. $\mathrm{O}$ autor, em Política e educação, esclarece que a educação é política por estar a serviço de valores e interesses de grupos e, por isso, reitera que "a prática educativa deve ser, coerentemente, um fazer desocultador de verdades e náo ocultador [...] É que há formas antagônicas de ver a verdade - a dos dominantes e a dos dominados. No fundo, ocultar ou desvelar verdades não é uma prática neutra" (FREIRE, 2001b, p. 41).

Lima (2002), na obra Organização escolar e democracia radical: Paulo Freire e a governação democrática da escola pública, defende que a proposta pedagógica, para e pela cidadania democrática, seja um plano que objetive a formação para o diálogo, a participação, a ingerência e democratização da escola pública. E essa luta e conquista implicarão um processo permanente de abertura, devolução, inserção e apropriação comunitária da escola.

Assim,

[a] grande questão ao avaliarmos nossas açôes é que não se faz o que se quer, mas o que se pode. Uma das condiçôes fundamentais é tornar possível o que parece impossível. A gente tem que lutar para tornar o que ainda não é possível. Isto faz parte da tarefa histórica de redesenhar e reconstruir o mundo. (FREIRE, 2002, p. 55)

Pode-se afirmar que é inerente ao ser humano a necessidade de ir além, projetar-se para o futuro. Assim, "não há história sem luta, sem projeto coletivo, sem conflitos, sem movimento de humanização, e é este conjunto de dimensóes que educando pessoas, pode vir a libertar" (PASSOS apud STRECK, 2010, p, 192). 


\section{Resultados: a integração das TIC ao Projeto Político-Pedagógico das escolas (Prouca)}

Projeto Político-Pedagógico: a integração das TIC ao currículo escolar

O primeiro documento a ser analisado será o da escola C. E. M. Professora Neyde Tonanni Marão. A escola está localizada na zona urbana da cidade de Votuporanga, no interior de Sáo Paulo. A unidade escolar faz parte do Programa Nacional de Renda Mínima, vinculado à Educação Bolsa-Escola. A iniciativa tem o objetivo de viabilizar a permanência das crianças beneficiárias com açóes socioeducativas, após o período das aulas. A implantação do projeto Escola Tempo Integral nas escolas municipais prioriza a socialização e a inclusão a uma vida saudável e plena de crianças de baixa renda e em risco.

A escola conta com a seguinte modalidade de ensino: de $1^{\circ}$ ao $5^{\circ}$ ano (Ciclo I) do ensino fundamental. No ano de 2010, o total de alunos era de 504. A unidade escolar é uma instituição importante para a comunidade, pois pais e filhos têm a expectativa de que a escola possa prepará-los para a cidadania e o trabalho.

Destaque-se, no documento, que a escola conta com infraestrutura e recursos para desenvolver a integração das TIC ao currículo escolar, uma sala de TV e vídeo e 01 sala de informática, porém não localizamos a informação se cada aluno dispóe de um laptop educacional para desenvolver os objetivos propostos.

A unidade escolar anuncia no documento sua missão: "Nossa missão é oferecer um ensino de qualidade e permanência dos alunos na escola para uma transformação na sociedade, para que eles possam interferir construtivamente na transformaçáo do seu meio" (PLANO ESCOLAR ANUAL, 2010, p. 6).

No documento que retrata o Projeto Político-Pedagógico, a escola expressa os seguintes objetivos gerais, na formação dos alunos do $4^{\circ}$ ano, do ensino fundamental:

I - O desenvolvimento da capacidade de aprender, tendo como meios básicos o pleno domínio da leitura, da escrita e do cálculo; 
II - A compreensão do ambiente natural e social, do sistema político, da tecnologia, das artes e dos valores em que se fundamenta a sociedade; III - O desenvolvimento da capacidade de aprendizagem, tendo em vista a aquisição de conhecimentos e habilidades e a formação de atitudes e valores; IV - O fortalecimento dos vínculos de família, dos laços de solidariedade humana e de tolerância recíproca em que se assenta a vida social. (PLANO ESCOLAR ANUAL, 2010, p. 76)

Logo em seguida, no Plano de Ensino de Língua Portuguesa, propóe-se desenvolver as seguintes habilidades, ao longo dos nove anos, no ensino fundamental:

Utilizar as diferentes linguagens-verbal, matemática, gráfica e corporal como meio de produzir, expressar e comunicar suas ideias, interpretar e usufruir das produçóes culturais, em contextos públicos e privados, atendendo a diferentes intenções e situaçóes de comunicação. Saber utilizar diferentes fontes de informação e recursos tecnológicos para adquirir e construir conhecimentos. (PLANO ESCOLAR ANUAL, 2010, p. 87)

Pode-se afirmar, pelos registros extraídos do documento que a unidade escolar tem, a intenção, no processo da alfabetização, de propiciar o amplo acesso e inclusão ao letramento digital. Pode-se inferir que, dentre os conhecimentos e habilidades que a escola anuncia garantir aos alunos, está a apropriação dos conhecimentos tecnológicos.

Nos planos de ensino, constatou-se que, nas séries iniciais, o uso e integração das TIC estão relacionados à utilização da TV e do vídeo. A partir do $4^{\circ}$ ano do ensino fundamental, localiza-se no Plano de Ensino de Língua Portuguesa (PLANO ESCOLAR ANUAL, 2010, p. 76-77) a menção da integração do computador portátil, a serviço da construção de conhecimentos. Em seguida, localizamos no Plano de Ensino da disciplina de Língua Portuguesa, do $5^{\circ}$ ano do ensino fundamental, a intenção de utilizar as TIC como ferramentas que contribuem na geração e construção de conhecimentos e como potencial de mudança na forma de ensinar e aprender de professores e alunos.

A seguir, apresentamos os materiais que estão a serviço da aprendizagem: "livros; literatura infantil; textos complementares; jornal, revistas, anúncios, panfletos, jogos pedagógicos; tecnologia eletrônica, videocassete, $D V D$, aparelho de som e o computador portátil" (PLANO ESCOLAR ANUAL, 2010, p. 93). 
Como narrativa para ação, a unidade escolar anuncia os projetos especiais que, durante o ano letivo, têm o objetivo de, ao alfabetizarem, ampliarem conhecimentos e conscientizarem: Caravançará; Hora da Leitura; Água e Vida; Valorização da Vida; Aula de Reforço; Família no Cinema; Escola de Tempo Integral; Preservação do Patrimônio; Sexualidade; Educando para o Trânsito; OBA - Olimpíada Brasileira de Astronomia e Astronáutica; Prouca - Um Computador por Aluno; Combate a Dengue; Teatro e Esporte na Escola.

Dentre os projetos acima desenvolvidos, localizamos anúncios de integração das TIC à proposta educacional nos seguintes: Água e Vida, Aula de Reforço, Escola de Tempo Integral e Combate a Dengue. É importante registrar que náo localizamos, no documento que retrata o Projeto Político-Pedagógico, a proposta educacional do Programa Um Computador Por Aluno.

No Projeto Água e Vida tem-se a intenção de convidar os alunos do $1^{\circ}$ ao $5^{\circ}$ do ensino fundamental, durante seis meses, pela pesquisa e leitura, a pensar, dialogar e construir conhecimentos sobre o tema Água. A proposta é a de integrar as TIC às práticas educativas a serviço da conscientização sobre o uso e preservação da água no mundo.

No processo do estudo, pretende-se empregar a seguinte metodologia: "A metodologia utilizada para a realização deste projeto se valerá de pesquisas no bairro, aula-passeio, vídeo educativo, software educativo, tabulação de pesquisas e gráficos, apresentação de resultados, discussóes e propostas de soluçóes, palestras e visitas" (PLANO ESCOLAR ANUAL, 2010, p. 14).

Nessa linha de análise, resgatamos no documento anúncios de integração das TIC ao Projeto Escola Tempo Integral. O Projeto propóe-se a criar espaços e oportunidades para que as crianças e seus familiares, nos momentos extraescolares, tenham a oportunidade de passar por vivências enriquecedoras, socioeducativas, como apoio aos trabalhos escolares, às práticas desportivas e culturais e à alimentação.

Sendo assim, o projeto tem a intenção de proporcionar aos alunos de baixa renda e em situação de risco, de $1^{\text {a }}$ à $4^{\text {a }}$ série, de ambos os períodos, durante o ano inteiro, atividades esportivas, oficinas ocupacionais, aulas de jardinagem, graffit, break, dança de salão, higiene e saúde, artesanato, fotografia e jornalismo, capoeira, teatro, contador de histórias, música e coral, descobrindo a matemática, informática e inglês.

Não localizamos, porém, o detalhamento das açôes, as dificuldades enfrentadas, as soluçóes criadas e as contribuições que os professores e alunos evidenciam no ensinar e aprender, a partir da integração das TIC às práticas educativas. 
Em seguida, o segundo documento é o da Escola Estadual Presidente Costa e Silva, localizada no estado de Tocantins. A unidade escolar oferece o ensino fundamental do $6^{\circ}$ ao $9^{\circ}$ ano. A escola, no ano de 2010, recebeu o prêmio Escola Referência Brasil, escolhida por cem educadores de escolas e instituições de ensino. Dentre seus principais objetivos, busca incentivar e criar mecanismos para que os pais participem de todas as atividades. Como resultado, a escola obteve o índice zero em evasão escolar.

No documento, a escola apresenta os recursos tecnológicos disponíveis à integração das TIC ao currículo: 01 retroprojetor, 05 televisores, 20 computadores, 06 impressoras, 02 escâneres, 02 aparelhos de som, 02 xerocopiadoras, 02 telas de projeção, 200 fitas de vídeo, 10 CDs educativos, 01 máquina fotográfica, 02 datashows, $123 \mathrm{DVDs}, 18 \mathrm{MCP}$ notebook, 01 antena parabólica e digital e 353 laptops, para cada aluno e professores.

No ano de 2010, o total de alunos era de 300 e 11 professores. Os alunos pertencem ao nível socioeconômico médio-baixo, sendo que a minoria dos alunos reside nas proximidades da escola. A maior parte mora em outros bairros, havendo também alunos da zona rural (fazendas e assentamentos).

Procurou-se resgatar, no documento que retrata o Projeto Político-Pedagógico da escola, as finalidades que norteiam sua ação pedagógica. Constatou-se no documento (PROJETO POLÍTICO-PEDAGÓGICO, 2011, p. 6), que sua construçáo, no ano de 2010 , contou com a representação dos sujeitos da instituição: equipe docente e discente, pais e comunidade. E que eles, conscientes do compromisso e do papel de cada um, buscam superar o abandono e repetência escolar.

Como narrativa para a ação, destaca-se o projeto Uma Visão Social ao Combate à Evasão Escolar, cujo objetivo é reduzir o índice de evasão para $0 \%$. Meta esta que foi concretizada, ao final de 2010. As estratégias adotadas foram o monitoramento diário de frequência dos alunos. Semanalmente, foram feitas ligaçóes telefônicas às famílias dos alunos faltosos e, a cada quinze dias, visitas domiciliares. Além disso, ofereceram duas aulas semanais de reforço durante o ano letivo. Portanto, o documento que retrata o Projeto Político-Pedagógico tem a pretensão de anunciar, pela profunda reflexão coletiva sobre a realidade da escola, "as finalidades, concepçóes e diretrizes, a partir das quais se originam todas as açóes, tornando-se um norte para a ação pedagógica, sendo também, um elemento de integração e articulação da comunidade escolar" (PROJETO POLÍTICO-PEDAGÓGICO, 2011 p. 6). 
A escola assume que desenvolve uma proposta educacional a partir dos saberes que os alunos trazem à escola, advindos de suas experiências de mundo. Um dos eixos fundamentais à elaboração da prática educativa dos professores é a busca da superaçáo do saber do senso comum dos alunos, pelos conhecimentos científicos. Assim, expressam que o "conhecimento não pode advir de um ato de 'doaçáo' que o educador faz ao educando, mas sim, de um processo que se realiza no contato com o mundo vivenciado, dinâmico e em transformação contínua." (PROJETO POLÍTICO-PEDAGÓGICO, 2011, p. 26).

Dentro desse contexto, a escola assume sua função social:

Queremos uma educação em que as pessoas, como sujeitos de seu crescimento humano, busquem sua identidade individual, social e global, situando-se criticamente no momento histórico, em que lhes compete viver, conviver e analisar criticamente a realidade. Como também, usufruir dos avanços científicos, tecnológicos, humanos, espirituais e os estritamente acadêmicos do mundo atual. (PROJETO POLÍTICO-PEDAGÓGICO, 2011, p. 24)

A escola expressa no documento os projetos significativos à alfabetização dos alunos e que terão continuidade: Projetos Valores que Transcendem os Espaços Formais da Escola; Uma Visão Social no Combate à Evasão Escolar, Gincana Cultural Aquarela, Projeto Treliças de Leitura, Projeto Liderança nas Escolas e Projeto Prouca.

É importante resgatar que, anualmente, a equipe pedagógica faz uma pesquisa avaliativa com o objetivo de compreender quais são os fatores que contribuem para a qualidade na aprendizagem dos alunos e quais dificultam.

Como impacto positivo nas aulas, avaliados como pontos fortes, estão os projetos: Programa Um Computador Por Aluno e a Proposta Pedagógica de Ensino por Blocos de Disciplinas.

Após análise do documento que retrata o Projeto Político-Pedagógico, pode-se inferir que não foram encontradas as práticas educativas, as dificuldades, as contribuiçóes e os desafios a respeito da integração das TIC ao currículo escolar. Considera-se de extrema relevância o fato de a escola convidar todos os sujeitos da comunidade escolar para que possam registrar no documento a proposta de integração das TIC e, em especial, o uso do laptop no currículo escolar.

O terceiro documento que retrata o Projeto Político-Pedagógico é o da Escola Estadual Roque Romeu Ramos. A unidade escolar está localizada em Ouro Verde de Goiás, estado de Goiás. A escola é formada por pequenos grupos comunitários, da zona rural. O colégio localiza-se no centro da ci- 
dade, com acesso a supermercados, correio, lojinhas, biblioteca municipal e praça. A água é tratada, porém, não há esgoto.

As modalidades oferecidas na unidade escolar são: ensino fundamental, do $2^{\circ}$ ao $9^{\circ}$ ano, e ensino médio, do $1^{\circ}$ ao $3^{\circ}$ ano. Do $2^{\circ}$ ao $5^{\circ}$ ano do ensino fundamental, a modalidade é a de tempo integral. $\mathrm{O}$ ensino fundamental é oferecido em nove anos, a começar nesta unidade do $2^{\circ}$ ano ao $5^{\circ}$ ano em tempo integral. Há 475 alunos e parte deles trabalha na horticultura e na ordenha. Faz-se mister acrescentar que também recebem alunos com necessidades especiais e contam com 01 professor intérprete, contratado para atender a demanda. Finalmente, o funcionamento ocorre nos turnos matutino, vespertino e noturno.

A unidade escolar recebeu do Programa Um Computador Por Aluno (Prouca), no final de 2011, 593 laptops. A estrutura da escola foi ampliada com a incorporação da extinta Escola Municipalizada de Matão, sendo possível a modulação da biblioteca escolar e do laboratório de informática. O espaço físico é amplo para a realização de atividades culturais, contando com um pátio grande e uma quadra de esportes. A escola conta com salas arejadas e claras, uma sala de vídeo e arte. A comunidade ouro-verdense utiliza o espaço escolar para seminários, reuniōes religiosas, políticas e sociais.

Em relação ao processo de construção do Projeto Político-Pedagógico, a informação é a de que o diretor (PROJETO POLÍTICO-PEDAGÓGICO, 2011, p. 17-18), eleito pelo voto da comunidade escolar, em parceria com o coordenador pedagógico, estimula a participação dos professores na reflexão e elaboração do documento. Então, observa-se que a intenção é a de "coordenar a elaboração, a implantação, a implementação, o monitoramento e a avaliação do Projeto Político-Pedagógico (PPP), do Regimento Escolar e do Plano de Desenvolvimento da Escola PDE.” Ao corpo docente, cabe: "Participar do planejamento e execução dos projetos coletivos da Unidade Escolar, especialmente do Projeto Pedagógico e PDE” (PROJETO POLÍTICO-PEDAGÓGICO, 2011, p. 19).

No documento que retrata o Projeto Político-Pedagógico, no diagnóstico que a escola apresenta, anunciam que os maiores desafios são inibir a reprovação e a evasão escolar. Constatou-se que a taxa geral de reprovação no ensino fundamental, do $1^{\circ}$ ao $9^{\circ}$ ano, foi a de $4.5 \%$ e a de evasão, de $2.3 \%$. No ensino médio, a taxa de reprovação foi a de $6.2 \%$ e a de evasão, de $13.8 \%$. Resgatamos no documento (PROJETO POLÍTICO-PEDAGÓGICO, 2011, p. 13) os problemas que receberam medidas emergenciais: a evasão no período noturno, devido à taxa de $35,8 \%$ e as altas 
taxas de reprovação nas disciplinas do ensino médio: Química - 42\%, Física - 42\% e História - 21\%. E no ensino fundamental, nas disciplinas de Matemática - 33\%, Geografia - 29\%, História - 26,6\%, Língua Portuguesa $25,5 \%$ e Ciências - 24\%. Destacam-se, ainda, dois fatores que contribuem para asseverar o quadro de problemas apresentados: a alta taxa de rotatividade dos professores e a ausência de qualificação de pessoal técnico-gerencial.

A partir dessa problemática, os profissionais da escola priorizaram o seguinte objetivo geral no plano curricular, para o ensino fundamental, do $1^{\circ}$ ao $9^{\circ}$ ano:

Proporcionar ao aluno o domínio da leitura, escrita e diferentes linguagens: verbal, matemática, gráfica, plástica e corporal - como meios para compreender o ambiente natural e social, o sistema político, científico, ético, as diferentes tecnologias, as artes e os valores em que se fundamentam a nossa sociedade, expressar e comunicar suas ideias e usufruir das produçóes culturais. (PROJETO POLÍTICO-PEDAGÓGICO, 2011, p. 21)

Além dessa intenção, apresenta-se na justificativa a seguinte pretensão:

Esta unidade escolar ministrará o Ensino Fundamental, à aplicação e execução de um plano de ensino, como procedimentos didáticos atualizados inspirados no "aprender a conhecer", "aprender a fazer" e "aprender a ser", o que significa selecionar estratégias de ensino que garantam a aprendizagem de conteúdos conceituais - (o que é preciso "saber"), conteúdos procedimentais - ("saber fazer"), conteúdos atitudinais - ("ser e conviver"). (PROJETO POLÍTICO-PEDAGÓGICO, 2011, p. 21)

Constatou-se, no objetivo geral do currículo do ensino fundamental e do ensino médio, que a escola tem a finalidade de proporcionar ao aluno o domínio da leitura e escrita em diferentes linguagens. "Como meios para compreender o ambiente natural e social, o sistema político, científico, éti$\mathrm{co}$, as diferentes tecnologias, as artes e os valores em que se fundamentam a nossa sociedade, expressar e comunicar suas ideias e usufruir das produçóes culturais." (PROJETO POLÍTICO-PEDAGÓGICO, 2011, p. 22). E, em seguida, anunciam acerca do ensino médio: "A formação básica do cidadão, mediante sua compreensão do ambiente político, tecnológico, artístico para o desenvolvimento de seus valores culturais, morais sociais e o fortalecimento dos vínculos de família e dos traços de solidariedade humana." (PROJETO POLÍTICO-PEDAGÓGICO, 2011, p. 27). 
Resgatou-se, no documento, que, na proposta curricular do ensino de Ciências do $6^{\circ}$ ao $9^{\circ}$ ano, denominado Um Currículo para a Aprendizagem dos Alunos, um dos eixos temáticos é: ciência, tecnologia e sociedade. Infelizmente, não encontramos informaçóes sobre os objetivos, os conteúdos e a metodologia para que compreendêssemos as finalidades da proposta educacional.

Ao apresentarem as matrizes curriculares das modalidades de ensino da unidade escolar à Secretaria de Estado da Educação, Subsecretaria Regional de Educação de Anápolis, observou-se que a escola registra na sua matriz curricular as atividades curriculares permanentes no Laboratório de Informática, inclusive com a carga horária durante o ano letivo.

Obtivemos as seguintes informações no documento sobre os Projetos Pedagógicos (PROJETO POLÍTICO-PEDAGÓGICO, 2011, p. 35), em especial o Prouca: "O Projeto UCA - Um Computador Por Aluno - no critério de eficácia - a expectativa é a de que melhore o processo ensino-aprendizagem. Os resultados obtidos refletem a melhoria na aprendizagem dos alunos." Além dessa menção, em relação ao Programa UCA, resgatamos o seguinte registro:

Em 2011 serão desenvolvidos os Projetos: Feira de Ciências, (UCA) - Um Computador por Aluno, Projeto 1000 - Passa a Bola e Práticas Esportivas entre outros, com o objetivo de associar os problemas sociais para despertar no alunado o interesse por uma melhor qualidade de vida. (PROJETO POLÍTICO-PEDAGÓGICO, 2011, p. 10)

Depreende-se assim, que o Programa Um Computador Por Aluno, no Colégio Estadual Roque Romeu Ramos, pode melhorar a qualidade de vida dos alunos, impulsionando novas e significativas aprendizagens. É importante acrescentar que, embora não tenhamos localizado nenhuma avaliação sobre o impacto do Prouca na aprendizagem dos alunos, validamos a voz dos sujeitos da escola que o avaliam como significativo.

Finalmente, sugerimos que a escola retome o documento que retrata o Projeto Político-Pedagógico e registre com informaçóes o processo de integração das TIC ao currículo escolar, como as dificuldades, as soluções criadas, os avanços e desafios presentes.

\section{Conclusão e sugestóes}

Para finalizar, temos a intenção de sintetizar os principais anúncios apresentados pelas três escolas, acerca do Programa Um Computador Por 
Aluno, sobre a integração das TIC ao currículo escolar, bem como apresentar algumas sugestóes.

Constatou-se nos documentos que retratam o Projeto Político-Pedagógico a intenção das escolas de contextualizar a leitura da palavra, a escrita e o cálculo matemático, a partir das experiências e dos saberes dos alunos, como ponto de partida e princípio fundante do processo de construçáo de conhecimentos. Compreende-se que essa decisão está a serviço da leitura crítica do momento histórico desses sujeitos.

Almeida e Valente (2011, p. 29) ressaltam que o importante é ter uma visão crítica sobre a integração das TIC ao currículo, pois as mídias e tecnologias não são recursos neutros e interferem nos modos de produzir cultura, de se relacionar e estar no mundo.

As escolas estão conscientes de seu papel na formação dos sujeitos sociais e consideram imprescindível registrar, no Projeto Político-Pedagógico, que o aluno terá acesso aos avanços científicos e tecnológicos, como saberes e habilidades para exercer sua cidadania de forma plena, no século XXI.

Evidencia-se, pelos anúncios feitos, que as TIC e, em especial, o laptop educacional, podem democratizar o acesso e a inclusão ao saber sistematizado. Certamente, o conhecimento científico sistematizado deve estar a serviço dos alunos para transformar suas experiências de mundo.

É importante acrescentar a necessidade de as escolas registrarem, nos documentos que retratam o Projeto Político-Pedagógico, o processo construído, as dificuldades e soluçóes encontradas, os avanços alcançados e os desafios presentes.

Destaque-se, ainda, que o Projeto Político-Pedagógico é a sistematização do constante processo de pensar e planejar a caminhada que se quer para a escola. Como instrumento teórico-metodológico que norteia as mudanças que se quer implantar na escola, torna-se fundamental eleger os sujeitos que, frequentemente, o retomem para registrar o processo e, assim, garantir ao plano global da instituição a visão da organicidade entre o particular e o geral.

Além desses destaques, reitera-se a importância da continuidade da formação permanente dos professores e gestores. Isso representa afirmar o compromisso do poder público em garantir, no lócus das escolas, a reflexão crítica do tecnológico ao pedagógico. A prática educativa inovadora só será possível ao longo desse processo de repensar a prática cotidiana. 
82 Polyphonía, v. 22/1, jan./jun. 2011

\section{Referências}

ALMEIDA, M. E. B.; VALENTE, J. A.. Tecnologias e curriculo: trajetórias convergentes ou divergentes? São Paulo: Paulus, 2011.

BOGDAN, R. C. Investigação qualitativa em educação: uma introdução à teoria e aos métodos. Portugal: Porto, 1994.

FREIRE, P. Ação cultural para a liberdade e outros escritos. 10. ed. São Paulo: Paz e Terra, 2002. . A educação na cidade. 5. ed. São Paulo: Cortez, 2001a. . Política e educação. 6. ed. São Paulo: Cortez, 2001b.

LIMA, L. Organização escolar e democracia radical. Paulo Freire e a governação democrática da escola pública. São Paulo: Cortez, Instituto Paulo Freire, 2002.

PLANO escolar anual. C. E. M. Professora Neyde Tonanni Marão. 2010.

Projeto Político-Pedagógico. Colégio Estadual Roque Romeu Ramos. Ouro Verde de Goiás. 2011.

. Escola Estadual Presidente Costa e Silva, Gurupi, 2010.

SCHÖN, D. A. Educando o Profissional Reflexivo: Um novo design para o ensino e a aprendizagem. Porto Alegre: Artes Médicas Sul, 2000.

STRECK, D. R.; REDIN, E.; ZITKOSKI, J. J. Dicionário Paulo Freire. Belo Horizonte: Autêntica. 2010.

VASCONCELOS, C. dos S. Coordenação do Trabalho Pedagógico: do Projeto Político-Pedagógico ao cotidiano da sala de aula. 11. ed. São Paulo: Libertad Editora, 2009. 